\title{
O PLANO DIRETOR DE ARACAJU E SUAS CONTRADIÇÕES: UMA ANÁLISE PRELIMINAR
}

\author{
Anselmo Belém Machado ${ }^{1}$
}

\begin{abstract}
Resumo: Este artigo tem o objetivo inicial de fazer uma análise crítica ao Plano Diretor de Desenvolvimento Urbano Sustentável de Aracaju e descrever a problemática urbana na cidade nos últimos anos. Com o processo de crescimento urbano intenso, Aracaju vem revelando a necessidade urgente de que seja elaborado um plano diretor de maneira democrática, que vise uma melhor qualidade de vida de sua população e de uma efetiva proteção ao meio ambiente. Em relação ao atual Plano Diretor de Desenvolvimento Urbano Sustentável de Aracaju, podemos afirmar que este "plano não é plano nem tão pouco pleno", uma vez que reflete os interesses de uma minoria privilegiada pois as decisões de alteração e interferência no espaço urbano foram definidas de maneira a favorecer os agentes produtores do espaço urbano e os grupos privilegiados que estão atrelados a estes agentes. Em suma, este plano diretor não é pleno, já que favorece a minoria da população privilegiada em detrimento da grande maioria excluída dos direitos fundamentais expressos na Constituição Federal do Brasil.
\end{abstract}

Palavras-Chave: Plano Diretor; Desenvolvimento Urbano Sustentável; exclusão social.

\section{Master plan and its Aracaju contradictions: a preliminary analysis}

\begin{abstract}
This article has as an initial objective to make a review to the Master Plan for Sustainable Urban Development in Aracaju. This paper also describes the issue of urban problems in the municipality of Aracaju in recent years. With the intense urban growth process, Aracaju has revealed the urgent need to be elaborated a master plan in a democratic manner, seeking a better quality of life of its population and an effective environmental protection. In relation to the current Master Plan for Sustainable Urban Development in Aracaju, we can say that this 'plan is not flat nor full', since this master plan reflects the interests of a privileged minority. Because we know that alteration and interference decisions in urban areas were defined to facilitate the producing agents of urban space and the privileged groups that are linked to these agents. Thus, this master plan is not full, since it favors the privileged minority of the population to the detriment of the majority excluded from basic rights expressed in the Federal Constitution of Brazil.
\end{abstract}

Key-Words: Master Plan, Sustainable Urban Development; social exclusion.

\footnotetext{
${ }^{1}$ Licenciado e Bacharel em Geografia pela Universidade Federal de Sergipe, Mestrado em Geografia pela Universidade Federal de Sergipe. Professor Adjunto 4 - Departamento de Geografia - Universidade Federal de Sergipe -UFS, Doutorando Universidade do Minho. E-mail: profufsbelem@ig.com.br DOI: 10.7154/RDG.2012.0024.0010
} 


\section{INTRODUÇÃO}

Este artigo foi escrito como tentativa de chamar a atenção para o problema do habitar em Aracaju, capital do Estado de Sergipe, que, segundo o Censo de 2010 tinha, à época, uma população de 552.365 habitantes (Diário Oficial da União, em 04-11-10). Aracaju é considerada uma cidade de porte médio, concentrando $27,12 \%$ da população total do Estado de Sergipe, que é de 2.036.277 habitantes (Idem). A capital tem o domínio econômico e cultural do Estado e nenhuma outra cidade chega a interferir no seu domínio. Em seu espaço urbano, Aracaju apresenta vários exemplos de problemas semelhantes aos das demais regiões metropolitanas do Brasil, tais como: alta concentração populacional, déficit habitacional, alta valorização imobiliária, segregação socioespacial, grande concentração de automóveis, poluição sonora e de fuligem, pouca arborização, crescente índice de criminalidade etc. Deste modo, necessita, urgentemente, de um plano diretor que atenda aos anseios da grande maioria de sua população, que vive em condições de habitação precária e sem saúde.

A elaboração de um plano diretor pelos órgãos municipais foi uma determinação do Estatuto da Cidade a partir de 2001. A obrigatoriedade de elaborar este plano diretor fez com que os grupos dominantes locais se articulassem para que pudessem continuar a ter vantagens com o processo de crescimento desordenado de Aracaju e sua região metropolitana. Mas o que era para solucionar os problemas urbanos de Aracaju foi feito para dificultar mais ainda a vida da maioria da população, que vive de maneira excluída e ocupando áreas de proteção ambiental permanente. Este artigo traz apenas uma análise inicial do plano diretor de desenvolvimento urbano sustentável de Aracaju, com a elicidação de várias contradições existentes nesta cidade capital, que é considerada, pela sua prefeitura, como "a cidade da qualidade de vida".

\section{Os agentes produtores do espaço urbano e o processo de domínio territorial urbano}

A cidade, principalmente a moderna e contemporânea, é o local onde se encontra o centro do poder da decisão sobre as diversas paisagens e diferentes índices de ocupação urbana. Nela, concentram-se as decisões dos grupos dominantes que são representados pelos "agentes produtores do espaço urbano" que, segundo Sposito (2008, p.24), citando Corrêa, são representados pelos proprietários dos meios de produção - personificados pelos donos 
de grandes indústrias e empresas comerciais - e estabelecem as dimensões de ocupações, definindo os tipos de espaços construídos. Os proprietários fundiários buscam o valor de troca do solo urbano mais do que o seu valor de uso. Segundo também os autores citados, os promotores imobiliários são responsáveis por operações que facilitam a compra e a venda de fragmentos da cidade. Essas operações são: a) Incorporação - escolha, divisão e qualificação dos lotes de terrenos ou dos edifícios para moradia ou produção de mercadorias; b) Financiamento - disponibilização de dinheiro necessário para o comprador se apropriar de um imóvel; c) Estudo técnico - adequação das obras aos parâmetros legais e avaliar possibilidades de comércio e de lucro; d) Construção:- definição das construtoras e as forças de trabalho necessárias para a construção dos imóveis; e) Comercialização transformação da mercadoria em capital-dinheiro, agora acrescido de lucros.

Ainda conforme os mesmos autores citados (Idem, p.26), outro agente produtor do espaço urbano é o Estado, que tem atuação em diferentes frentes, e é marcado pelos conflitos de interesses dos diferentes membros da sociedade de classes, bem como pela aliança entre eles. Mas o que está bem claro é que os grupos dominantes utilizam a instituição do "Estado" para legitimar as ocupações dos espaços urbanos, mesmo que estas ocupações ocorram em área considerada de preservação permanente. Como exemplo, podemos citar o conjunto habitacional do Governo Federal Sérgio Vieira de Mello, que foi mais uma obra do Governo Federal do Programa - PAR (Programa de Arrendamento Residencial) construída em Aracaju sobre áreas de manguezais, localizada na porção leste do bairro São Conrado.

Assim, podemos evidenciar que os agentes produtores do espaço urbano estão sempre articulados entre si, de forma que, continuam agindo para transformar a cidade, mas sempre em busca de seus interesses. Por outro lado, em detrimento dos interesses das populações (inclusive as mais carentes), estes agentes ocupam áreas de preservação, burlando a legislação ambiental e fazendo o "papel" de bonzinhos, à medida que facilitam a construção de conjuntos habitacionais nestas áreas, onde, na maioria das vezes não existe a infraestrutura urbana básica e, quando tem, estão localizadas dentro do mangue e/ou em áreas sujeitas à grande possibilidade de enchentes, quer seja em épocas de chuvas ou mesmo pela cheias das marés. Contudo, o autor a seguir descreve que existe também outro agente que interfere profundamente na estrutura urbana e social da cidade.

Os Grupos Sociais excluídos que são aqueles que demandam, sobretudo, moradia nas cidades. Como o acesso à moradia ocorre em um processo 
seletivo por causa das próprias condições da cidade capitalista, a casa é, em grande parte, produzida pelo sistema de autoconstrução em loteamentos periféricos em relação à cidade mais densamente ocupada ou até mesmo em loteamentos clandestinos localizados, no extremo, em áreas públicas ou de proteção ambiental. (SPOSITO, 2008, p.27).

Sposito (2008, p.27-28) esclarece que a cidade cresce conforme as suas características históricas próprias, comportando três tipos de crescimento: o primeiro é o populacional; o segundo é o componente de crescimento horizontal, que é definido pelo perímetro de sua planta urbana; e o terceiro é o crescimento vertical. Como o perímetro da cidade é limitado, então o crescimento vertical é estimulado, ou seja, o aumento do número de edifícios em vários bairros da cidade, com diferentes preços, de acordo com a sua localização, em áreas mais ou menos valorizadas da cidade. O processo de crescimento da cidade nestes três tipos de crescimentos (populacional, crescimento horizontal e vertical) só corrobora com o crescente processo de segregação socioespacial, tornando a cidade cada vez mais mercantilizada e excludente. Então como podemos (todos que compõem a cidade) conviver pacificamente em uma cidade desumanizada? Esta é a pergunta que não quer calar.

Os políticos - que, na esfera citadina, são os prefeitos e vereadores - agem como representantes do Estado de forma a legitimar a ação dos demais produtores do espaço urbano. Os excluídos (os ocupantes de favelas, cortiços e a população dispersa em diversas ocupações inadequadas na cidade) também exercem influência e pressão social por moradia no espaço da cidade. Tal pressão é, no entanto, ainda muito fraca, em virtude dos grupos excluídos não serem organizados nem terem, ainda (no caso da cidade de Aracaju), ações planejadas e articuladas de enfrentamentos mais concretos. Quanto mais a cidade cresce, mais poder de influência este grupo tem, principalmente nas regiões metropolitanas ou nas cidades em que a ocupação humana na sua periferia rural-urbana chega a ultrapassar os seus limites político-administrativos. Como exemplos, podemos citar o que já está ocorrendo em Aracaju, nas suas zonas de expansão urbana, localizadas na região sul da cidade (mais fortemente no Mosqueiro e Aruana) e, mais recentemente, nos arredores do bairro Santa Lúcia.

O processo de segregação socioespacial e o papel do Plano Diretor como agente minimizador do caos urbano; o caso específico da cidade de Aracaju 
O processo de ocupação urbana é remoto e, desde o início do desenvolvimento das forças produtivas, as cidades vêm passando por inúmeras transformações cujos responsáveis não vêm tendo a preocupação adequada com o meio ambiente nem, tampouco, têm interesse em tornar o viver urbano menos injusto. As transformações ocorridas no processo de crescimento urbano e na multiplicação das cidades em todo o mundo vêm historicamente agredindo à natureza e, por conseguinte, têm reflexos na qualidade de vida da população citadina. Neste contexto, as cidades, sejam pequenas, médias ou grandes, vêm crescendo de maneira desordenada, o que tem provocado um espaço urbano desorganizado, poluído e segregado. Com isto, os grupos dominantes vêm sendo continuamente favorecidos, e continuam ampliando os problemas urbanos a cada dia.

Para tentar minimizar estes problemas os cidadãos de maior poder aquisitivo buscam residir em condomínios fechados e com toda uma estrutura de segurança. Chegamos a um nível de caos urbano, em que os privilegiados não conseguem mais viver de maneira plenamente tranquila, uma vez que aonde se vá é preciso estar acompanhado de segurança e a moradia tem se tornado uma "prisão". Por outro lado, para a grande maioria da população, que vive à margem deste contexto, em que a convivência com o caos urbano é uma rotina, com todo o tipo de falta de infraestrutura, residindo em moradia inadequada, (quando têm) falta de alimentos (principalmente os de boa qualidade), de remédios e muitos outros problemas sociais. Com tudo isto, muitos destes moradores que são excluídos consideram que é "normal" viverem e habitarem de maneira precária, dizendo: "Deus quis assim". São moradores excluídos por imposição e não por opção, uma vez que já nasceram dentro deste contexto social urbano de maneira desestruturada, sem moradia, sem infraestrutura básica, sem empregos, apenas vivendo de subempregos e até se alimentando das coletas que buscam nas lixeiras da sua cidade.

Com o aumento da intensidade deste processo de desestruturação urbana, a sociedade civil organizada percebeu a grande necessidade de se tentar minimizar o caos urbano e tentar estruturar melhor a cidade, buscando um viver e morar urbano mais adequado, ou seja, mais humanizado. Entretanto, para que a cidade se torne mais humanizada, é necessário que o grande percentual de seus habitantes consigam residir de maneira digna e se desloquem livremente pela cidade para que possam usufruir das benesses que o sistema urbano moderno pode lhes "oferecer". Assim, surgiram as primeiras tentativas para se ordenar a cidade e tentar minimizar o caos existente. Estas tentativas foram frutos de 


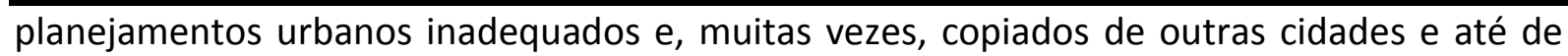
outros países.

Mas estes primeiros planos de ordenamento do território da urbe não foram realizados com o intuito de minimizar o caos urbano; ao contrário, foram realizados projetos de "organização" do espaço, construídos de maneira a aumentar ainda mais a segregação socioespacial em escala mundial.

Com a consolidação do modo de produção capitalista, o crescimento urbano - a arquitetura e a paisagem - passa a se dar de forma diversificada. As novas paisagens e "cores", as novas técnicas de construção e novos produtos da revolução industrial revelaram outras perspectivas em relação ao conceito de habitar ou do que era entendido como paisagem urbana. (MACHADO, 1996, p.67).

Consequente desse processo, a cidade de Aracaju também tem recebido as influências decorrentes das inovações tecnológicas pelas quais vêm passando o mundo, produzindo, assim, novas paisagens e novos conceitos de moradia. Mas estas inovações, naturalmente, dentro do contexto capitalista, são usufruídas por uma minoria privilegiada que reside nos bairros mais elitizados da cidade.

O Brasil, como todos os países que estão dentro do contexto da globalização, vem recebendo as influências deste processo de crescimento desordenado e também da tentativa de se tentar minimizar este problema, porém, infelizmente, tem seguido um ritmo semelhante ao se arriscar a "tapar o céu com a peneira", ao tentar resolver o problema afastando os grupos humanos desfavorecidos para uma área mais distante do centro da cidade ou de áreas mais privilegiadas, isto é, estes grupos são deslocados por indução ou imposição para bairros onde reside um contingente populacional de menor ou nenhum poder aquisitivo. Mas apenas esta seleção territorial por extratos socioeconômicos não tem resolvido o problema: pelo contrário, as questões referentes à falta de infraestrutura básica, moradia inadequada, falta de uma boa alimentação e saúde precária têm favorecido para o aumento da segregação socioespacial.

Este processo de segregação socioespacial ocorre também em outras regiões mundiais, certamente com suas especificidades e diferentes intensidades em cada país. Podemos citar o caso europeu, em que os bairros da lata ou bairros sociais surgidos na década de sessenta revelaram a intenção dos governos destes países em tentar minimizar a problemática da criminalidade, dos contrastes sociais e da falta de moradia para a população mais carente. 
Com o passar dos anos, foi constatado que a criação dos bairros sociais não resolveu o problema da segregação socioespacial e, em muitos casos, até os agravou ainda mais.

Num exemplo mais específico, podemos destacar o que descreve António Pedro Ferreira, citando a socióloga Isabel Guerra Ferreira, quando se refere à situação problemática dos bairros sociais de Portugal: "Os sucessivos casos de criminalidade violenta são potenciados pela construção massiva de bairros sociais, uma solução que não é utilizada na Europa desde os anos $70[\ldots]^{\prime \prime}$

(2008, p.1). Segundo este autor, a socióloga reforça ainda mais tal questão quando afirma que "A concentração de população socialmente homogênea, mesmo quando é culturalmente heterogênea, traz problemas de socialização negativa" (Idem). Continuando com a mesma citação, a socióloga ainda dá sugestões sobre a atuação do Estado, que deveria subsidiar a moradia dos menos favorecidos em áreas dispersas da cidade:

No seu entender, deveria ser aproveitado o mercado imobiliário de forma que as famílias possam ser alojadas de maneira dispersa. O Estado, acrescentou, deveria apoiar no arrendamento, cobrindo o valor que o agregado familiar não conseguisse suportar. (FERREIRA, 2008, p.01).

Mesmo na Europa, onde o processo de reestruturação urbana está mais avançado, podemos constatar a existência da segregação urbana. No caso de Portugal, que segue as diretrizes da União Europeia (que também está atrelada ao processo do capitalismo mundial), evidenciamos a necessidade de uma nova estratégia de planejamento urbano, em que possam ser aplicadas ações mais humanizadas e menos segregadas. Mas, mesmo com tantas dificuldades, consideramos que haja uma exceção de bairro social que tenha dado certo, como é o caso do Bairro Social das Andorinhas, localizado na cidade de Braga. Segundo pesquisa no site da associação de moradores deste bairro (AMBA: Associação de Moradores do Bairro das Andorinhas), e conforme constatações in loco em junho de 2011, existem neste bairro social várias atividades visando a integração e socialização de sua população. Podemos citar algumas tais como: a própria criação desta Associação de Moradores, a construção da sede da Associação, a instalação da Internet na sede para os moradores e sócios, queima do Judas, celebração da Páscoa, filmagens de eventos, debates sobre a violência doméstica, além de várias outras atividades de socialização, como a realização de vários passeios, apresentação de palestras sobre saúde e o projeto Voa (Valorizar, Olhar, Aprender). Este projeto pretende envolver a população do bairro em ações cívicas, artísticas 
e socializantes de forma que integre a comunidade e torne os moradores deste bairro mais responsáveis. Alem disso, ocorrem comemorações de datas festivas, convênios com entidades (Ágora Bracarense, Bragahabit, Uminho, Câmara) etc. São muito interessantes estas ações socializantes realizadas por esta Associação, esperamos que sejam para o bem de seus moradores.

Voltando ao caso brasileiro e, especificamente, à cidade de Aracaju, temos constatado que os planos diretores estão sendo realizados, mas o caos urbano se torna, a cada dia, inevitável. Assim, após vários anos de debates e na tentativa de democratização, foi elaborada no Brasil a Constituição Federal de 1988, que, a partir de então, teve um destacado papel de tentar "assegurar o exercício dos direitos sociais e individuais, o bemestar, o desenvolvimento, a igualdade e a justiça como valores supremos de uma sociedade fraterna, pluralista e sem preconceitos, fundada na harmonia social”. (OLIVEIRA, 2001, p. 3). Para Oliveira (2001), a nova Constituição de 1988 teve grande avanço quando da "inclusão dos artigos 182 e 183, compondo o capítulo da Política Urbana" (idem, p.3). Desta forma, o Estatuto da Cidade, , depois de inúmeros debates, proposições dos parlamentares e de vários vetos, foi aprovado em Brasília em 2001, conforme a Lei no 10.257, e está organizado em cinco partes:

\begin{abstract}
Na primeira, são abordadas as diretrizes gerais do Estatuto, apresentando as metas que se desejam ver atendidas e que envolvam todas as esferas do poder público - municipal, estadual e federal". Na segunda, se aborda a gestão democrática nas cidades, importante conquista dos movimentos populares, hoje, gravada em lei. A seguir, o plano diretor é apresentado, enfatizando seu papel como instrumento básico da política de desenvolvimento e de expansão urbana, as suas recentes características e as possibilidades para atuação na esfera local. Na quarta parte, se encontram os instrumentos previstos para se alcançar os importantes princípios de função social da propriedade, de justa distribuição dos benefícios e dos ônus decorrentes da urbanização e a primazia do interesse público nas ações relativas à Política Urbana. (OLIVEIRA, 2001, p.5).
\end{abstract}

Portanto, a partir de 2001, todas as cidades acima de 20 mil habitantes e suas regiões metropolitanas deveriam elaborar os seus planos diretores para tentarem se adequar ao Estatuto da Cidade. Decorrente disso inúmeros planos diretores começaram a ser criados e implantados nas cidades por todo o Brasil. Mas a grande maioria, para não dizer quase todos, foi fruto de acordos realizados entre empresas e gestores municipais. Estas empresas e políticos estão atrelados aos agentes produtores do espaço urbano. Com isto, foram 
elaborados planos diretores com inúmeras falhas, o que tem gerado a continuidade e 0 aumento da desordem urbana em vez de tentar minimizá-la. De tal modo também foi elaborado, há mais de dez anos, o plano diretor de desenvolvimento urbano de Aracaju. Este Plano Diretor passou por mais de um ano em revisão, que foi concluída em março de 2012. A questão é a seguinte: por quem foi feito o plano diretor? E qual o objetivo deste plano diretor?

Uma análise do documento sugere que a maneira como foram escritos os seus artigos só tem a favorecer os grupos privilegiados em detrimento da grande maioria da população. 0 plano diretor de desenvolvimento urbano de Aracaju segue um traçado de reprodução do status quo da cidade e, com isto, tem favorecido a reprodução de uma classe social privilegiada e de um grande contingente populacional de excluídos. O Plano Diretor de desenvolvimento urbano de Aracaju deveria estabelecer limites de ocupação ordenada do solo, respeitando a existência de boa infraestrutura e ocupação dos terrenos, e que todas as áreas ou bairros fossem analisadas as condições de redes de esgotos, de sistema de drenagem, de ocupação residencial, da gestão dos resíduos sólidos, etc., de maneira controlada e adequada a um projeto com qualidade técnica reconhecida.

Aracaju, hoje, vive um grande problema decorrente da falta de planejamento urbano mais adequado a um modelo citadino, pois, nos últimos trinta anos vêm crescendo de maneira muito rápida. Vários novos conjuntos habitacionais foram construídos e grandes contingentes populacionais foram deslocados para a região da grande Aracaju. Como exemplo, podemos citar Araújo (2006, pp.238/239), que fornece uma tabela com dados de 2003 da Cehop (Companhia Estadual de Habitação e Obras Públicas): “Entre os anos de 1968 e 2002 foram construídos em Aracaju 45 Conjuntos Habitacionais Populares, com 13.961 unidades construídas." Estes programas habitacionais só provocam a especulação imobiliária, favorecendo mais e mais a concentração populacional em áreas sem infraestrutura adequadas, nem programas integrados de auxílio à saúde, à educação, etc. Neste sentido podemos citar mais uma vez o mesmo autor, que descreve que

Em uma primeira análise, as políticas urbanas destinadas a resolver o problema do déficit de moradias em Sergipe, particularmente em Aracaju, colocam em xeque o papel do Estado no processo de produção do espaço que, além de responsabilizar-se pelo fluxo migratório de Aracaju e sua periferia imediata, atua como agente imobiliário e não como mediador dos conflitos urbanos decorrentes de sua própria ação política. (Idem. p.242). 
Esta estratégia foi realizada tentando minimizar a concentração populacional na região "core" da capital, área esta composta pelo centro antigo da cidade e os bairros localizados mais ao sul da cidade. Mas isto não tem resolvido a questão, uma vez que a população aumenta continuamente e que uma parte da região metropolitana, composta, principalmente, pelos municípios de Nossa Senhora do Socorro, São Cristóvão e Barra dos Coqueiros, o que tem seus problemas urbanos aumentados de maneira crescente, tais como a criminalidade, com aumento do uso de drogas, furtos de residências e veículos), , crescente homicídios, roubos a mão armada entre outros tipos de crimes e. Também tem aumentado a ocupação e o impacto ambiental junto às áreas de preservação permanente nas áreas próximas aos estuários dos rios existentes nestes municípios. Ainda existem inúmeros outros problemas, tais como: infraestrutura precária, inexistência de postos de saúde suficientes, poucas escolas, fraco policiamento, etc. Todos estes problemas têm crescido com o aumento da população nesta região, e que foram intensificados com a construção de pontes, que têm triplicado o deslocamento populacional diário, e a valorização imobiliária, visto que a presença das pontes, nestes municípios, agregou valor de troca ao solo urbano, como é o caso do município de Barra dos Coqueiros, localizado na região leste do Estado de Sergipe, com a construção da ponte "João Alves Filho", que interliga este município vizinho à capital, e também com a inauguração da ponte Joel Silveira, em março de 2010, que interliga o sul de Aracaju com o litoral do município de Itaporanga D’Ajuda, facilitando o deslocamento da população e turistas para as praias existentes nos povoados da Caueira e do Abais.

A cidade de Aracaju necessita de um Plano Diretor de Desenvolvimento Urbano Sustentável e, para que isto ocorra, deve existir uma ordenação de ocupação do solo de maneira adequada com um determinado coeficiente de aproveitamento. Segundo o Plano Diretor de Desenvolvimento Urbano Sustentável de Aracaju, em seu Artigo 189,

Para garantir a ocupação do solo de forma adequada às características do meio físico, bem como garantir o equilíbrio climático da cidade, serão observadas as seguintes normas urbanísticas no Código de Parcelamento, uso e ocupação do solo: I-Taxa de ocupação; II- taxa de permeabilidade; III Recuos e afastamentos; IV - coeficiente de aproveitamento; V - classificação de usos". O Coeficiente ou Índice de Aproveitamento: É a relação entre a área total construída e a área total do lote ou gleba. O índice máximo é aplicado a uma determinada zona da cidade, que limita a área máxima edificável em um lote. (PDDU, 2011, p.26). 
Quanto maior o índice de ocupação do solo, maior será o número de pessoas vivendo por metro quadrado. A cidade tem que ser analisada de maneira diferenciada, de modo que cada bairro ou área de zoneamento seja analisado conforme a quantidade de sua população, o tipo de terreno, a proximidade a áreas de preservação e que tipo de edificação já existe no local. Mas, da maneira como o Plano Diretor está redigido hoje, ele só tende a piorar este cenário e a cidade não crescerá de maneira sustentável.

Dessa forma, é importante planejar a cidade em todos os seus aspectos. Com a globalização, essa tarefa torna-se mais árdua, isto porque o tempo se acelera bem como os fluxos que estruturam a rede também se alteram com intensa rapidez, o que produz um ambiente extremamente mutável; essa capacidade de mutação constante faz com que as estratégias percam o valor usual em pouco tempo, assim, é importante planejar tendo em vista essa flexibilidade estratégica, visando antes de tudo à importância do elemento humano e sua capacidade administrativa, e ansiando resultados bem como flexibilidade. Enquanto se pautar o planejamento urbano apenas em aspectos quantitativos e documentais, aviltando o potencial estratégico humano, teremos ações pouco eficazes, uma vez que números e documentos não revelam os anseios e necessidades da sociedade. (FARIA, 2009, p.164).

Aracaju não foge a esta regra, pois sabemos que a globalização está influenciando as cidades mundialmente. Portanto, precisamos valorizar mais "o potencial humano" e levar sempre em consideração suas reais necessidades.

Outro problema recente que está afetando mais fortemente a cidade de Aracaju é a questão da mobilidade urbana. A quantidade de automóveis, motocicletas e caminhões circulando nas ruas aracajuanas só têm se intensificado. Segundo o Departamento Estadual de Trânsito de Sergipe (DETRAN), em agosto de 2011 existia, em Aracaju, um total de 228.567 veículos em circulação. Estão na lista destes veículos os automóveis de passeio, as motocicletas, os ônibus e caminhões pequenos. Segundo esta mesma fonte dos dados, ocorreu um crescimento impressionante de 183,8\%no total de automóveis no período de 2001 a 2011. Atualmente, está em processo de discussão o Plano Diretor de Desenvolvimento Urbano de Aracaju e, entre as alterações propostas, uma questão referente ao capítulo $V$, da política de transportes, tráfego e sistema viário, Artigo 80, que, em seu item I, descreve: “Desenvolver o sistema de transporte em que o uso coletivo prevaleça sobre o uso individual." (DIÁRIO OFICIAL DE ARACAJU, 5-09-2011). A sociedade civil organizada está tentando incluir este 
item como fundamental para o início da tentativa de soluções para minimizar o trânsito caótico de Aracaju, que ocorre nos horários das 6 às 7 e das 18 às 19 horas.

Mais recentemente (em 03-01-12), foi aprovada a Lei no 12.587/2012, que regulamenta a política nacional de mobilidade urbana no Brasil. Esperamos que, com esta Lei, a prefeitura possa, e queira realmente, adequar mais a cidade ao cidadão, ou seja, que o caos urbano seja mais controlado e que a cidade se torne mais humanizada, com mais ciclovias, mais passarelas para pedestres, mais árvores para tornar a cidade mais oxigenada, abertura de novas vias de acessos, melhores transportes coletivos, hora de descanso e melhores salários para os motoristas de ônibus, novas ruas e avenidas mais largas, menos carros no mesmo espaço nas horas mais críticas do trânsito, edifícios de garagens, metrô de superfície, rodízio dos automóveis, corredores específicos para ônibus, etc.

Segundo a reportagem de Mariana Oliveira realizada em 25-10-2009 e publicada no site G1.globo.com, com base nos dados do Instituto Brasileiro de Geografia e Estatística (IBGE) e do Departamento Nacional de Trânsito (DENATRAN), a frota de veículos cresceu $240 \%$ em oito anos nas maiores cidades do país. Segundo esta fonte, a cidade de Aracaju (SE) é a que tem o menor percentual de crescimento entre as capitais do Nordeste, com $12 \%$ de crescimento, no período de 2001 a 2009, enquanto Teresina (PI) teve um crescimento, no mesmo período, de 107\%. Mas é bom frisar que, segundo o IBGE, a área administrativa de Aracaju é de $182 \mathrm{~km}^{2}$ e a de Teresina é de $1.392 \mathrm{~km}^{2}$. Portanto, a área de Teresina é bem maior que a área de Aracaju, e por isso suporta uma maior quantidade de automóveis. Nesse sentido, em Aracaju, a concentração de automóveis nas ruas da cidade é bem significante.

As avenidas e ruas de Aracaju não têm mais espaço para esta quantidade de automóveis, que aumenta de maneira assustadora. Para tentar minimizar este problema, seria necessário aumentar o quantitativo de vias de interligação ao redor do perímetro urbano de Aracaju, e que o transporte coletivo de massa fosse multiplicado e melhorado em sua qualidade, além da construção denovas ciclovias e estimular os cidadãos a pedalar.

O Plano Diretor de Aracaju passou por uma série de audiências públicas até março de 2012, inclusive com a participação da sociedade civil "organizada", representada pelos seus pequenos grupos, por algumas associações e entidades. Embora não tenha poder de deliberação, foi uma atitude louvável, mas precisamos deixar bem claro que é o poder público municipal que tem o poder de decisão final. A sociedade civil tem contribuído, mas 
os agentes produtores do espaço urbano têm seus interesses próprios e que são divergentes dos da grande maioria da população aracajuana e também da população de sua região metropolitana. Basta analisar a segregação socioespacial pela qual passa a cidade e observar como foram e são construídos os edifícios de luxo, sem respeitar os limites e recuos definidos na lei de uso do solo urbano. Não só Plano Diretor de Aracaju é falho; de modo geral, todos os planos diretores no Brasil são falhos. A grande maioria da população não participou das audiências e nem poderia, dentro deste contexto, e não existe a possibilidade de sua participação em forma de seminários, audiências e reuniões de profissionais. A população não entende esta "linguagem". Segundo Villaça (2005), os Planos diretores foram falhos, pois não seguiram as necessidades reais das populações mais carentes e sim os interesses dos grupos privilegiados. Acompanhando este raciocínio, podemos afirmar que a população está à margem de embates teóricos. A grande maioria da população é carente não só de casa, alimento e saúde. É carente também para entender este contexto de ideias, planos, mapas, artigos etc. Para o autor citado não existe, de fato, a participação popular.

A "Participação Popular" conferiria um toque de democracia, igualdade e justiça às decisões políticas. Ela passou a ser divulgada como uma espécie de vacina contra a arbitrariedade, a prepotência e a injustiça. Com ela, todos se tornariam iguais perante o poder público. É essa ilusão que a recente ênfase, em Plano Diretor Participativo - querendo ou não - procura inculcar na opinião pública. $O$ que raramente aparece é que os grupos e classes sociais têm não só poderes político e econômico muito diferente, mas também diferentes métodos de atuação. Diferentes canais de acesso ao poder e, principalmente - algo que se procura sempre esconder diferentes interesses. Evidentemente num país desigual como o Brasil, com uma abismal diferença de poder político entre as classes sociais, conseguir uma participação popular democrática - que pressuporia um mínimo de igualdade - é difícil. Essa é a principal razão da "ilusão da Participação Popular". Assim, os debates públicos seriam apenas a ponta do iceberg, ou seja, aquilo que não aparece é muito maior do que a parte que aparece. (VILLAÇA, 2005, p.50).

Neste sentido esta tese é reproduzida também em Aracaju, onde constatamos quase nenhuma participação popular de maneira efetiva. Os Planos Diretores têm seus donos e estes não são da classe popular. Estes donos constroem os Planos Diretores seguindo os seus interesses e desejos, que não são os da grande maioria da população.

Terminamos fazendo uma citação dentro deste raciocínio descrito acima, que reforça a nossa tese diante das contradições existentes, tanto no Plano Diretor de Aracaju como de todos realizados no Brasil e America Latina: "Os planos diretores fracassaram não só em São 
Paulo, mas em todo o Brasil e a América Latina. Fracassaram não só porque eram falhos, mas porque tomaram os desejos pela realidade" (SINGER, 1995, p.177). Assim, resta-nos, como estudiosos da academia, propor ideias para minimizar os seus efeitos e, quem sabe, reescrever mais um novo Plano Diretor de Desenvolvimento Urbano, realmente sustentável para Aracaju.

\section{CONSIDERAÇÕES FINAIS}

A problemática do crescimento das cidades existe desde os tempos remotos, mas, com o processo de urbanização mundial, principalmente após as revoluções industriais, esta só tem se agravado. Nas últimas décadas as inovações tecnológicas trouxeram inúmeras soluções para vários problemas relacionados às questões do viver urbano, tais como descobertas nas áreas da saúde, na engenharia, na área automobilística, na área das telecomunicações etc., mas, com a intensidade e com o descontrole deste processo de urbanização, os problemas urbanos foram sendo multiplicados e irradiados mundialmente, principalmente com a globalização. Nesse sentido, o mundo ficou mais interligado com os avanços na área tecnológica, nos meios de transporte e, mais recentemente, na área da telecomunicação (principalmente com a Internet 3G, wi-fi, etc). Decorrente disso, as distâncias foram vencidas e as decisões que atingem as cidades são tomadas rapidamente, o que tem favorecido o processo de segregação socioespacial, tornando as cidades menos humanizadas. Assim, a necessidade de se tentar minimizar os problemas e ordenar a ocupação urbana é uma decisão que já está atrasada frente aos conflitos urbanos que estamos vivenciando em um ritmo muito acelerado. A proposta de realização de um planejamento adequado à boa qualidade de vida e de proteção contínua ao meio ambiente é fator primordial para se tentar minimizar este caos urbano. No entanto, a maneira como o atual plano diretor de desenvolvimento urbano sustentável de Aracaju foi escrito só contribui para aprofundar a heterogeneidade econômica e a segregação socioespacial de seu espaço construído, contribuindo, deste modo, para tornar a cidade cada vez mais desumana. Buscando minimizar estes problemas é escrevemos este artigo, no intuito de minimizar esta situação problemática da situação urbana de Aracaju. 


\section{REFERÊNCIAS BIBLIOGRÁFICAS}

ARAÚJO, Hélio Mário de (Org.) et al. - O Ambiente Urbano (Visões geográficas de Aracaju), São Cristóvão: Editora UFS, 2006.

FARIA Leonardo - Planejamento estratégico, Estatuto da Cidade e Plano Diretor. (métodos e instrumentos de organização e gestão do espaço urbano). In: Revista on line: Caminhos da Geografia, V.10, no 32, dez/2009, pp.162-170.

MACHADO, Anselmo Belém Machado - A origem da cidade (breves reflexões teóricas), In: Revista Vivência, CCHLA/UFRN, v.10, no 1⁄2, jan/dez, 1996, p.61-69.

OLIVEIRA, Isabel Cristina Eiras de - Estatuto da cidade; para compreender, Rio de Janeiro: IBAM/DUMA, 2001.

SINGER, Paul - Capitalismo: Sua evolução, sua lógica e sua dinâmica, São Paulo: 1995.

SPOSITO, Eliseu Savério - Redes e Cidades, São Paulo: UNESP, 2008.

VILLAÇA, Flávio - As llusões do Plano Diretor, (Publicado em agosto de 2005) In: http://www.flaviovillaca.arq.br/pdf/ilusao pd.pdf

AMBA- Associação dos moradores do Bairro das Andorinhas. Localizado na freguesia de São Vicente, cidade de Braga-Norte de Portugal.

Assessoria de Desenvolvimento Estratégico da Companhia de Estado Habitação e Obras Públicas (CEHOP) /Sergipe, 2003.

DETRAN - Departamento Estadual de Transito do Estado de Sergipe-Nordeste do Brasil, dados referente ao mês de agosto de 2011.

Diário Oficial do Município de Aracaju - Atos do Poder Executivo - 05 de setembro de 2011.

FERREIRA, Antonio Pedro. Portugal usa modelo ultrapassado de bairros sociais. Jornal Expresso, Lisboa, 19 de agosto de 2008. Caderno atualidade, página 01. Publicado no link: 
sociais=f391537\#ixzz1qK0v9XT2.

Lei de Mobilidade Urbana do Brasil no 12.587. Criada em 03 de Janeiro de 2012.

PAR - Programa de Arredamento Residencial da Caixa Econômica Federal - Governo Federal do Brasil.

PDDUS - Plano Diretor de Desenvolvimento Urbano Sustentável do Município de Aracaju, versão provisória do Projeto de Lei complementar no 06/2010 de 19 de novembro de 2010.

Site: http://g1.globo.com/Noticias/Carros.Reportagem de Mariana Oliveira, publicada em 25-10-09. Título: "Frota de veículos cresce $240 \%$ em oito anos nas maiores cidades brasileiras". Foram utilizados, neste artigo, alguns dados da tabela de evolução da frota de veículos nas maiores cidades, referente à Aracaju e Teresina.

Artigo recebido em 10/04/2012.

Artigo aceito em 12/06/2012. 